\title{
Renal tubular injury by glyphosate-based herbicide
}

\author{
Takahide Kimura $^{1} \cdot$ Takeshi Yokoyama $^{1} \cdot$ Masayuki Tanemoto $^{1}$
}

Received: 29 July 2020 / Accepted: 21 August 2020 / Published online: 1 September 2020

(c) Japanese Society of Nephrology 2020

Keywords Acute kidney injury $\cdot$ Glyphosate $\cdot$ Herbicide $\cdot$ Mitochondrial toxicity

A 78-year-old woman was admitted to our hospital with acute kidney injury (AKI), which developed 5 days after suicidal glyphosate-based herbicide (GBH) ingestion. She had oliguria with renal impairment (serum creatinine level $12.9 \mathrm{mg} / \mathrm{dL}$ ). Vigorous hydration could not resolve her oliguria, and hemodialysis treatment was initiated. Histological examination of renal needle biopsy found tubular injury, which was prominent in proximal tubules, but no apparent glomerular abnormalities (Fig. 1). The presented proximal tubular epithelial vacuolar degeneration was observed throughout the biopsy specimens. After 3 weeks of hemodialysis treatment, her renal function recovered gradually, and she discharged dialysis independently.

Although considered to be minimally toxic to human, GBH-poisoning presents several symptoms including AKI [1]. The AKI is attributed to hypovolemic shock by the surfactant ingredients of GBH [2]. However, the renal histology of epithelial injury in proximal tubules, the mitochondriaabundant nephron segment, indicated participation of the glyphosate mitochondrial toxicity in the AKI [3].

\section{Compliance with ethical standards}

Conflict of interest The authors have declared that there is no conflict of interest.

Research involving human participants and/or animals This article does not contain any studies with human participants or animals performed by any of the authors.

Masayuki Tanemoto

mtanemoto-tky@umin.ac.jp

1 Division of Nephrology, Department of Internal Medicine, International University of Health and Welfare School of Medicine, 13-1 Higashi-Kaigan-Cho, Atami, Shizuoka 413-8790, Japan

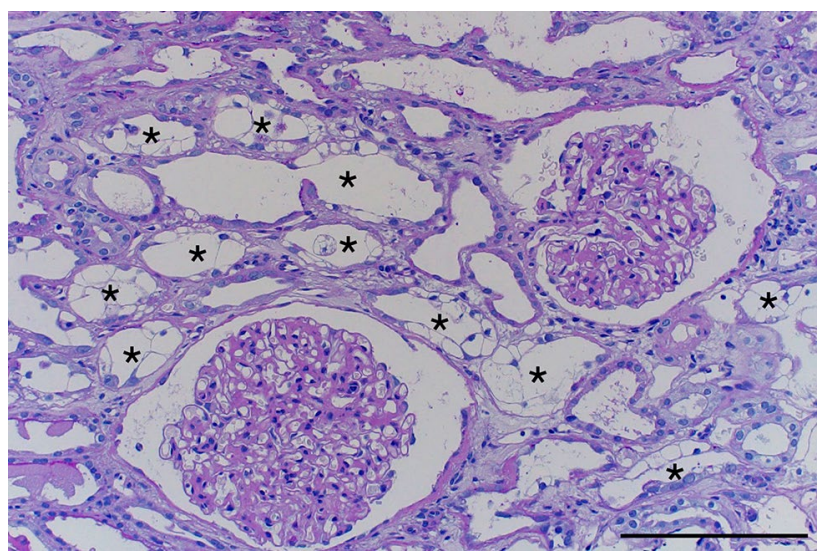

Fig. 1 Light microscopic image of renal biopsy specimen showing epithelial damage, which is prominent in proximal tubules (asterisks). Periodic acid-Schiff stain, Scale bar $100 \mu \mathrm{m}$

Informed consent Informed consent was obtained from the patient.

\section{References}

1. Talbot AR, Shiaw MH, Huang JS, Yang SF, Goo TS, Wang SH, Chen CL, Sanford TR. Acute poisoning with a glyphosate-surfactant herbicide ('Roundup'): a review of 93 cases. Hum Exp Toxicol. 1991;10:1-8.

2. Seok SJ, Park JS, Hong JR, Gil HW, Yang JO, Lee EY, Song HY, Hong SY. Surfactant volume is an essential element in human toxicity in acute glyphosate herbicide intoxication. Clin Toxicol (Phila). 2011;49:892-9.

3. Luo L, Wang F, Zhang Y, Zeng M, Zhong C, Xiao F. In vitro cytotoxicity assessment of roundup (glyphosate) in L-02 hepatocytes. J Environ Sci Health B. 2017;52:410-7.

Publisher's Note Springer Nature remains neutral with regard to jurisdictional claims in published maps and institutional affiliations. 